\title{
TEKNOLOGI PENANGKAPAN IKAN BOMBO CAKALANG DI PERAIRAN IWOIMENDAA KABUPATEN KOLAKA SULAWESI TENGGARA
}

\author{
Bombo Cakalang, A Fishing Gear Technology in Iwoimendaa Water, Kolaka Regency Southeast \\ Sulawesi \\ Oleh: \\ Rita L. Bubun ${ }^{1 *}$, Amir Mahmud ${ }^{2}$, Riswal Alam³
${ }^{1}$ Program Studi Pemanfaatan Sumberdaya Perikanan, Fakultas Perikanan dan Ilmu Kelautann, Universitas Muhammadiyah Kendari.rita.lbubun@umkendari.ac.id
2Program Studi Pemanfaatan Sumberdaya Perikanan, Fakultas Perikanan dan Ilmu Kelautann, Universitas Muhammadiyah Kendari.amir.mahmud@umkendari.ac.id
3Program Studi Pemanfaatan Sumberdaya Perikanan, Fakultas Perikanan dan Ilmu Kelautann, Universitas Muhammadiyah Kendari.riswal_alam@gmail.com \\ * Korespondensi: rita.lbubun@umkendari.ac.id
}

Diterima: 20 November 2020; Disetujui: 20 September 2021

\begin{abstract}
Bombo cakalang is a traditional fishing gear used by fishermen in Iwoimendaa Waters, Kolaka Regency, Southeast Sulawesi. Technical aspects of fishing technology using bombo cakalang have not been published scientifically. The objective of this study was to describe the technical aspects of bombo cakalang related to its materials, construction, fishing methods and fishing ground of targeted species in Iwoimendaa waters. This research applied a survey method and data were collected through direct observation, followed by qualitative and quantitative analysis. The results show that materials of the fishing gear include nets made of nylon monofilament (PA), net frames made of bamboo, drawstring ropes made of multifilament polyethylene (PE) and support poles made of "tiro tasi" wood. The construction of bombo cakalang fishing gear consists of a net with a hanging ratio (E1) of 0,47 and (E2) of 0.0031, a net frame (buoy), drawstring, support poles, a buoyant force of $1.037 \mathrm{Kgf}$ and a sinking force of $0.303 \mathrm{Kgf}$. The principle of the fishing method is trapping, tangling and deceiving the targeted fish. Potential fishing ground is the coastal waters of Bone Bay at coordinates of $03^{\circ} 78^{\prime} 77^{\prime \prime}-03^{\circ} 79^{\prime} 44^{\prime \prime}$ South Latitude and $21^{\circ} 068^{\prime} 32^{\prime \prime}-121^{\circ} 110^{\prime} 07^{\prime \prime}$ East Longitude. Sea surface temperature (SST) ranged from $25^{\circ} \mathrm{C}-28^{\circ} \mathrm{C}$, while salinity ranged from $31 \%$ - $33 \%$.
\end{abstract}

Keywords: net frame, hanging ratio, Bone Bay.

\section{ABSTRAK}

Bombo cakalang adalah alat tangkap tradisional yang digunakan oleh nelayan di Perairan Iwoimendaa, Kabupaten Kolaka, Sulawesi Tenggara. Aspek teknik teknologi penangkapan ikan bombo cakalang belum terpublikasi secara ilmiah. Tujuan penelitian ini adalah mendeskripsikan aspek teknik teknologi penangkapan bombo cakalang terkait bahan alat, konstruksi, metode penangkapan dan daerah penangkapan ikan cakalang di Perairan Iwoimendaa. Metode penelitian yang digunakan adalah metode survei dengan pengumpulan data melalui observasi langsung di lokasi penelitian. Analisis data menggunakan analisis kualitatif dan kuantitatif. Hasil penelitian adalah bahan alat penangkapan ikan bombo cakalang yaitu jaring dari bahan nylon monofilamen (PA), bingkai jarring dari bamboo, tali kolor dari multifilamen polyethylene (PE) dan tiang penyangga dari kayu "tiro tasi". Konstruksi alat tangkap bombo cakalang terdiri dari jaring dengan hanging ratio 
(E1) sebesar 0,47 dan (E2) sebesar 0,0031, bingkai jaring (pelampung), tali kolor, tiang penyangga, gaya apung sebesar $1,037 \mathrm{Kgf}$ dan gaya tenggelam sebesar 0,303 Kgf. Metode penangkapan ikan adalah menggunakan prinsip menjebak (trapping), menjerat (tangling) dan deception (menipu) ikan target. Daerah penangkapan ikan di pesisir Teluk Bone pada koordinat $03^{\circ} 78^{\prime} 77^{\prime \prime}-03^{\circ} 79^{\prime} 44^{\prime \prime}$ Lintang Selatan dan $21^{\circ} 068^{\prime} 32^{\prime \prime}-121^{\circ} 110^{\prime} 07^{\prime \prime}$ Bujur Timur. Suhu permukaan laut (SPL) berkisar antara $25^{\circ} \mathrm{C}$ $-28^{\circ} \mathrm{C}$. Salinitas berkisar antara $31 \%$ - 33\%

Kata kunci: bingkai jaring, hanging ratio, Teluk Bone.

\section{PENDAHULUAN}

Teknologi penangkapan ikan dalam arti luas dapat mencakup beberapa hal yaitu bahan alat penangkapan ikan, konstruksi alat tangkap, metode penangkapan ikan, daerah penangkapan ikan, alat bantu penangkapan, komposisi hasil tangkapan ikan dan tingkat keramahan lingkungan alat tangkap. Teknologi penangkapan ikan yang diterapkan oleh masyarakat nelayan dalam upaya memperoleh hasil tangkapan optimum berbeda-beda pada masing-masing daerah penangkapan ikan. Hal ini disesuaikan dengan target utama ikan yang akan ditangkap.

Ikan cakalang (Katsuwanus pelamis) merupakan salah satu target utama nelayan dan produk unggulan daerah Sulawesi Tenggara. Distribusi ikan cakalang berada pada seluruh wilayah perairan Sulawesi Tenggara, di bagian timur dan selatan yang terletak pada Wilayah Pengelolaan Perikanan (WPP) 714 Laut Banda dan di bagian barat terletak pada WPP 713 Teluk Bone.

Kecamatan Iwoimendaa merupakan salah satu wilayah pesisir Sulawesi Tenggara yang berbatasan langsung dengan WPP 713 Teluk Bone. Kegiatan pemanfaatan sumberdaya perikanan yang berasal dari laut salah satunya yaitu jenis ikan cakalang (Katsuwanus pelamis). Hasil observasi pada kegiattan penangkapan ikan cakalang (Katsuwanus pelamis) di Perairan Kecamatan Iwoimendaa dilakukan dengan berbagai macam alat tangkap. Alat tangkap yang digunakan oleh nelayan antara lain pancing tonda (troll line), rawai (long line), pancing ulur (hand line), mini purse seine, gill net, sero dan perangkap tradisional yang disebut bombo cakalang.

Bombo cakalang yang digunakan oleh nelayan di Kecamatan Iwoimendaa merupakan salah satu jenis alat tangkap yang digunakan untuk menangkap ikan pelagis yang sifatnya bergerombol khususnya ikan cakalang. Hasil observasi menunjukkan bahwa alat tangkap bombo cakalang prinsip kerjanya masuk dalam dua kategori alat penangkapan ikan, yaitu kombinasi antara jaring insang (gill net) dan pancing tonda (troll line). Kombinasi metode penangkapan ikan dan desain alat penangkapan ikan pada dua alat tangkap bombo cakalang yaitu ikan tertangkap pada insangnya dan alat tangkap dioperasikan dengan cara ditonda menelusuri perairan.

Teknologi penangkapan ikan tradisional bombo cakalang di Kecamatan Iwoimendaa merupakan salah satu bentuk alat tangkap yang saat ini belum ada kajian khusus dalam bentuk penelitian dan publikasi ilmiah terkait aspek teknik, sehingga perlu dilakukan kajian awal terkait hal tersebut. Kajian aspek teknik terkait alat tangkap bombo cakalang perlu dilakukan, mengingat ikan yang menjadi target tangkapan adalah ikan cakalang (Katsuwanus pelamis) yang masuk dalam kategori ikan ekonomis penting. Hasil tangkapan yang dihasilkan rata-rata sudah berukuran layak tangkap, sebagaimana dijelaskan dalam penelitian Jamal et al. (2011) bahwa ukuran length at first of maturity (Lm) ikan cakalang di Teluk Bone rata-rata berukuran lebih dari $40 \mathrm{~cm}$. Berdasarkan uraian tersebut maka tujuan penelitian yaitu mendeskripsikan secara lengkap mengenai teknologi penangkapan alat tangkap bombo cakalang yang digunakan di Kecamatan Iwoimendaa Kabupaten Kolaka Sulawesi Tenggara. Teknologi penangkapan ikan yang dimasksud dalam kajian ini antara lain bahan alat penangkapan ikan, konstruksi alat tangkap, metode penangkapan ikan, dan daerah penangkapan ikan. Informasi mengenai teknologi penangkapan ikan dari aspek teknik alat tangkap bombo cakalang dapat menjadi bahan kajian dasar dan pengkayaan inovasi perikanan tangkap dengan bahan alat, metode penangkapan, kontruksi dan daerah penangkapan ikan yang berbeda dengan alat tangkap ikan cakalang lainnya dan dapat dimasukkan dalam Klasifikasi Alat Penangkapan Ikan Indonesia.

\section{METODE}

Penelitian dilaksanakan pada September 2018 - Maret 2019. Lokasi penelitian di 
perairan Kecamatan Iwoimendaa Kabupaten Kolaka Sulawesi Tenggara. Perairan Kecamatan Iwoimendaa berbatasan langsung dengan WPP 713 Teluk Bone. Lokasi Penelitian dapat dilihat pada Gambar 1.

Metode penelitian yang digunakan adalah metode survei Metode ini digunakan untuk mendeskripsikan hal-hal yang terkait teknologi penangkapan ikan bombo cakalang di perairan Kecamatan Iwoimendaa Kabupaten Kolaka Sulawesi Tenggara. Data yang dikumpulkan dalam penelitian ini antara lain data primer dan sekunder. Pengumpulan data primer dilakukan melalui observasi dengan mengikuti operasi penangkapan ikan bombo cakalang dan wawancara. Penentuan jumlah responden yang di wawancara secara langsung dengan mengambil seluruh (populasi) jumlah nelayan bombo cakalang sebanyak 10 responden. Observasi bertujuan untuk mengamati secara langsung bahan alat penangkapan ikan, konstruksi alat tangkap, metode penangkapan ikan, daerah penangkapan ikan, alat bantu penangkapan. Observasi dilakukan dalam dua tahap yaitu tahap pertama identifikasi bahan alat penangkapan ikan, konstruksi alat tangkap dan alat bantu penangkapan ikan. Tahap kedua yaitu identifikasi daerah penangkapan ikan dan metode penangkapan ikan. Identifikasi daerah penangkapan ikan dilakukan dengan pengambilan titik koordinat menggunakan GPS (Global Positioning System) bersamaan dengan pengukuran parameter oseanografi. Pengukuran parameter oseanografi terdiri dari : (1) suhu permukaan laut menggunakan thermometer digital; (2) transparansi air laut menggunakan seichi disck; (3) salinitas air laut menggunakan handrefraktometer. Data sekunder bersumber dari bukubuku referensi yang mendukung informasi ilmiah dalam penelitian.

Analisis data yang digunakan dalam penelitian ini terdiri dari analisis kualitatif dan kuantitatif. Analisis kualitatif digunakan untuk mendeskripsikan aspek teknis mengenai bahan alat, desain konstruksi, metode penangkapan ikan dan daerah penangkapan ikan alat tangkap bombo cakalang. Analisis kuantitatif digunakan untuk menentukan hanging ratio, gaya apung dan gaya tenggelam pada alat tangkap bombo cakalang. Formula untuk menghitung aspek teknis tersebut antara lain :

\section{Hanging ratio}

Perhitungan hanging ratio dimaksudkan untuk menentukan besarnya bukaan mata jaring alat tangkap bombo cakalang pada saat dioperasikan, terutama saat menjerat hasil tangkapan. Formula hanging ratio (Sembiring et al. (2016) yaitu :

$E=\frac{L}{L_{0}} \times 100 \%$

Dimana:

$E=$ Hanging ratio

$L=$ Panjang jaring sebelum dibentangkan

$L_{0}=$ Panjang jaring setelah dibentangkan

\section{Gaya Apung (B)}

Gaya apung pada alat tangkap menunjukan besarnya kemampuan suatu benda untuk mengapung di atas air pada saat terdapat benda lainnya dibawahnya (jaring). Formula gaya apung (Martasuganda 2008) yaitu :

$B=W\left(\gamma_{w} / \gamma-\gamma_{w}\right)$

Dimana:

$B=$ Gaya apung (kgf)

$W=$ Gaya gravitasi

$\gamma_{w}=\quad$ Massa jenis air laut $(1,025)$

$\gamma=$ Massa jenis benda

\section{Gaya Tenggelam $(S)$}

Gaya tenggelam pada alat tangkap menunjukkan kemampuan dari bagian alat tangkap tersebut tenggelam yang dinyatakan dalam satuan kgf . Formula gaya tenggelam (Martasuganda 2008) yaitu :

$S=W\left(\gamma_{w}-\gamma_{w} / \gamma\right)$

\section{HASIL}

\section{Deskripsi Alat Tangkap Bombo Cakalang}

Bombo cakalang merupakan alat tangkap hasil pemikiran inovatif para nelayan melalui modifikasi beberapa alat tangkap. Bagian utama dari alat tangkap ini berupa jaring yang bentuknya menyerupai gill net (jaring insang). Metode pengoperasiannya menyerupai alat tangkap tonda (troll line) dan sifatnya menyerupai alat tangkap trap. Tiga prinsip kerja dan model alat tangkap ini tergabung dalam satu unit penangkapam bombo cakalang.

Target ikan untuk bombo cakalang yaitu target utamanya adalah jenis ikan cakalang. Namun menurut para nelayan yang mengoperasikan alat tangkap tersebut dalam satu kali trip penangkapan, hasil tangkapan bombo cakalang dapat memperoleh jenis-jenis ikan pelagis lainnya seperti ikan tenggiri (Scomberomurus sp). Gambar alat tangkap bombo cakalang dapat dilihat pada Gambar 2. 


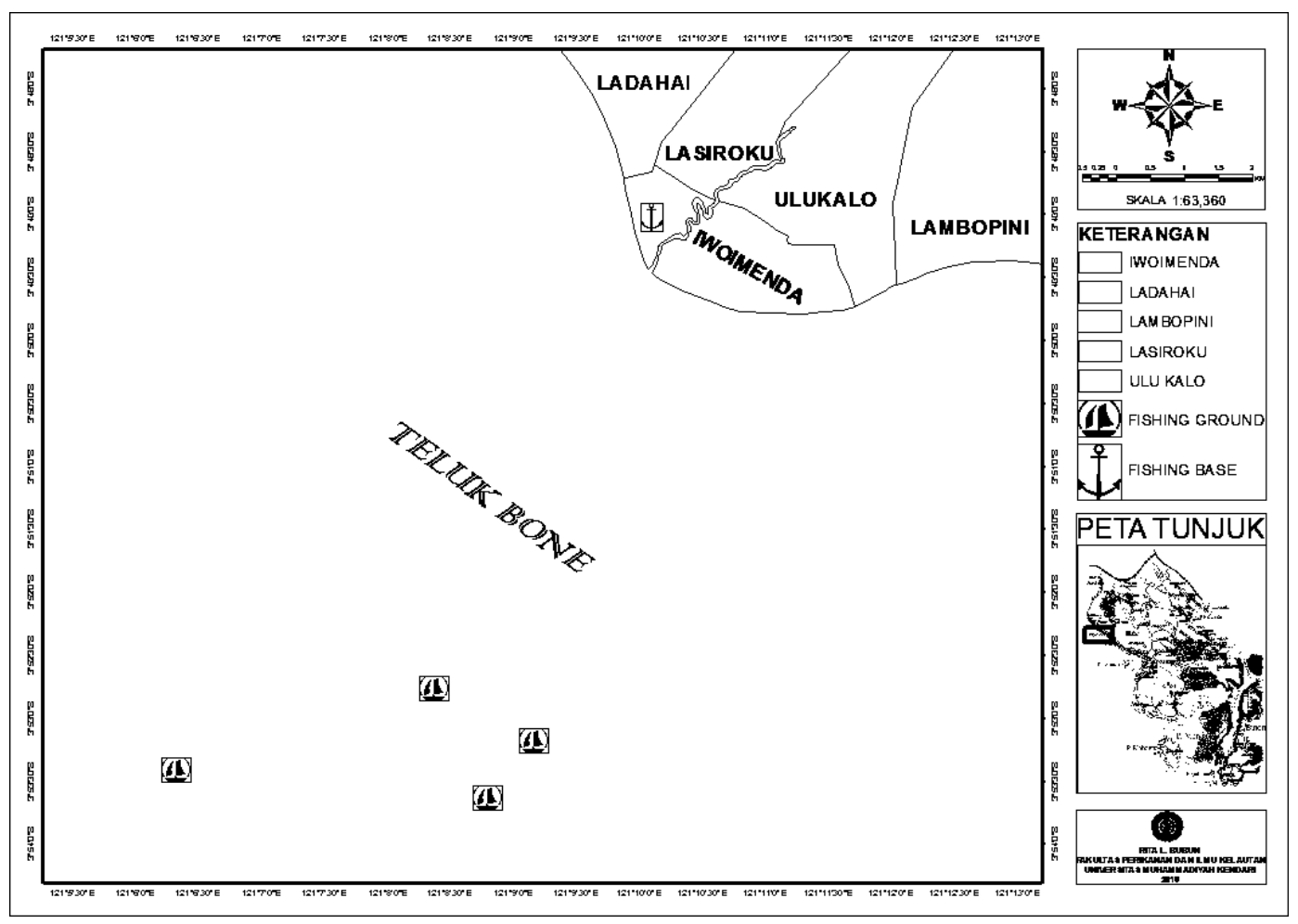

Gambar 1 Peta daerah penangkapan ikan

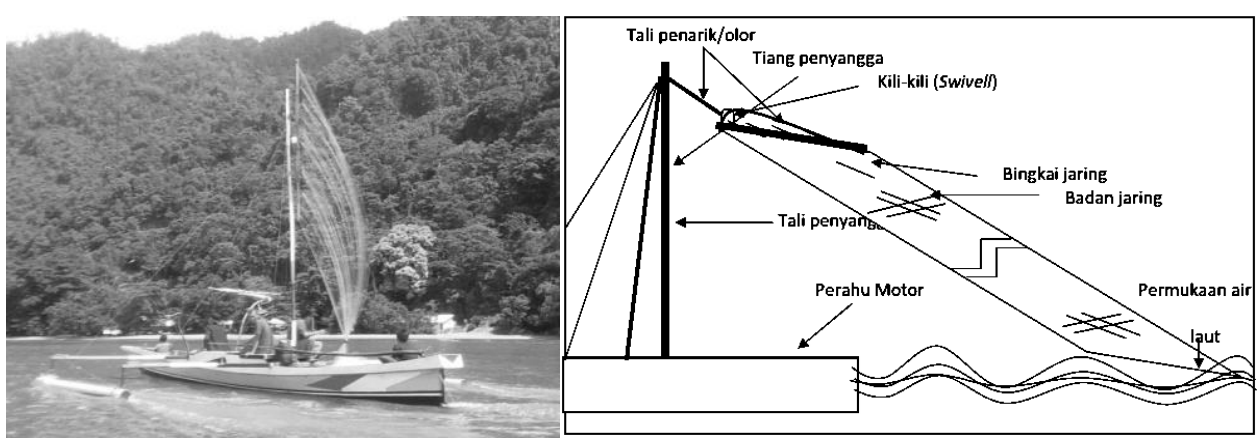

A

B

Gambar 2 Alat tangkap bombo cakalang: (A) sebelum dioperasikan;

(B) bagian-bagian alat tangkap setelah dioperasikan

\section{Konstruksi Alat Tangkap Bombo Cakalang}

Konstruksi bombo cakalang merupakan konstruksi alat tangkap yang unik. Umumnya alat tangkap memiliki tiga komponan utama yaitu pelampung, badan (jaring/tali) dan pemberat. Namun konstruksi bombo cakalang hanya memiliki pelampung, badan dan tali olor (tali penarik). Pelampung terbuat dari bahan kayu atau bambu. Badan terbuat dari bahan jaring nylon monofilamen (PA). Tali olor terbuat dari bahan multifilamen polyethylene (PE). Kontruksi alat tangkap bombo cakalang dapat dilihat pada Gambar 3.
Gambar 3 menunjukkan bagian-bagian dari alat tangkap bombo cakalang. Penjelasan mengenai bagian-bagian tersebut diuraikan sebagai berikut :

\section{Jaring}

Jaring merupakan bagian utama dari alat tangkap bombo cakalang. Badan jaring bombo cakalang terbuat dari bahan nylon monofilamen (PA), panjang 40 meter, lebar jaring 3 meter, mesh size (ukuran mata jaring) 4,5 inchi, diameter benang $0,35 \mathrm{~mm}$, berat jaring $3 \mathrm{~kg}$. Ukuran jaring nylon monofilamen (PA) dapat dilihat pada Tabel 1. 
Hasil wawancara dengan nelayan terkait pemilihan bahan jaring nylon monofilamin (PA), sebab bahan tersebut tidak banyak meyerap air dan memiliki daya apung yang tinggi. Kekurangan dari bahan nylon monofilamin (PA) lebih mudah putus pada saat hasil tangkapan ikan berusaha melepaskan diri dari jaring. Kusumasteti et al. 2017 menjelaskan bahwa kekuatan putus (breaking strenght) pada benang nylon monofilamen (PA) yang direndam di air laut selama satu bulan sebesar 6 kgf -7 kgf dan nilai kemuluran (elongation) sebesar 36\% - 38\%. Hal ini berarti bahwa jaring nylon monofilamen (PA) yang digunakan pada alat bombo cakalang memiliki kekuatan putus yang lebih rendah sebab bombo cakalang hanya berada di air laut pada saat operasi penangkapan.

\section{Bingkai Jaring}

Bombo cakalang tidak memiliki tali ris yang berfungsi sebagai tempat melekatnya pelampung dan badang jaring. Alat tangkap ini dilengkapi dengan bingkai jaring yang berfungsi sebagai pelampung dan tempat melekatnya jaring. Panjang bingkai jaring 3 meter. Bingkai jaring bombo cakalang terbuat dari bahan kayu coklat. Spesifikasi ukuran bingkai jaring bombo cakalang dapat dilihat pada Tabel 2. Bahan pembuatan bingkai jaring bombo cakalang selain dari kayu dapat juga terbuat dari bahan lain seperti bambu. Namun nelayan setempat jarang menggunakan bahan dari bambu, sebab bahan dari bambu mudah pecah dan menyerap air. Pemilihan bahan kayu cokelat sebagai bingkai jaring bombo cakalang karena bahan tersebut selain sifat tidak mudah patah, ringan dan mudah mengapung di atas permukaan air, bahan tersebut mudah didapat di sekitar wilayah Desa Iwoimendaa Kecamatan Iwoimendaa Kabupaten Kolaka.

\section{Tali olor atau Tali Penarik}

Tali olor atau tali penarik pada bombo cakalang menggunakan multifilamen polyethylene (PE) dengan panjang 50 meter. Panjang tali olor sekitar $1,25 \%$ dari panjang jaring bombo cakalang. Arah pintalan tali olor yaitu S. Spesifikasi tali olor dapat dilihat pada Tabel 3.

Panjang tali olor bombo cakalang tidak lebih panjang dan tidak lebih pendek dari $1,25 \%$ panjang jaringnya. Hal ini terkait dengan kegiatan setting dan hauling bombo cakalang saat menemukan gerombolan ikan di perairan. Apabila tali olor lebih pendek daripada panjang jaring, maka jaring akan terpuntal, sebab pada saat setting seluruh badan jaring belum berada di perairan, tali olor sudah terbentang seluruhnya. Hal ini menyebabkan gerombolan ikan yang sudah ada di sekitar catchable area menjauhi wilayah tersebut. Apabila tali olor lebih panjang dari panjang jaring, maka pada saat hauling (penarikan alat tangkap) membutuhkan waktu lebih lama, akibatnya kualitas hasil tangkapan ikan dapat menurun akibat gerakan meronta ikan dalam jeratan jaring.

\section{Tiang Penyangga}

Tiang penyangga bombo cakalang terbuat dari bahan yang berbeda dengan bingkai jaring. Tiang penyangga terbuat dari kayu yang lebih kuat dan tidak mudah dibengkokkan. Nelayan setempat menyebut bahan kayu tiang penyangga dengan nama lokal daerah setempat yaitu kayu "tiro tasi". Fungsi tiang penyangga sebagai tempat dikaitkan tali olor atau tali penarik. Letak tiang penyangga pada kapal antara 3 meter $-3,5$ meter dari buritan. Tinggi tiang penyangga 5 meter. Spesifikasi tiang penyangga dapat dilihat pada Tabel 4.

Pemasangan tiang penyangga harus tetap memperhatikan stabilitas kapal pada saat olah gerak di atas permukaan air terutama saat setting dan hauling. Berdasarkan hal tersebut, maka ukuran panjang tiang penyangga $50 \%$ dari panjang kapal 10 meter. Apabila kurang dari 50\% panjang kapal, maka akan mempengaruhi aktivitas saat setting jaring. Jaring tidak dapat melayang secara sempurna sehingga jaring dapat terpuntal sebelum menjerat ikan di perairan.

\section{Hanging ratio $(\mathrm{E})$, Gaya Apung (B) dan Gaya Tenggelam (S)}

Hidrodinamika air laut dan bahan pembuatan alat tangkap merupakan bagian yang mempengaruhi desain dan kontruksi alat tangkap termasuk bombo cakalang. Hanging ratio $(\mathrm{E})$ pada alat tangkap yaang terbuat dari jaring menjadi hal penting yang perlu diketahui, sebab mempengaruhi bukaan jaring pada saat alat tangkap dioperasikan. Hasil pengamatan di lapangan, hanging ratio pada bombo cakalang terdiri dari dua bagian yaitu $\mathrm{E} 1$ dan E2. E1 yaitu hanging ratio yang kerutan mata jaring renggang. E2 yaitu hanging ratio yang kerutan mata jaring rapat.

Hasil analisis hanging ratio pada interval kerutan mata jaring renggang 21,3 cm diperoleh nilai E1 sebesar 0,47 (47\%) dan hanging ratio pada kerutan mata jaring 
rapat $0,5 \mathrm{~cm}$ diperoleh nilai $\mathrm{E} 2$ sebesar 0,0031 $(0,31 \%)$. Desain jaring bombo cakalang yang menyerupai jaring gill net sangat dipengaruhi oleh nilai hanging ratio. Fachrudin dan Hudring (2012) diacu dalam Pertiwi et al. (2017) menjelaskan bahwa secara umum jaring gill net memiliki hanging ratio horizontal sebesar 0,5\%. Apabila hanging ratio lebih kecil dari 0,5\%, maka ikan cenderung akan terpuntal oleh jaring. Apabia hanging ratio lebih besar dari 0,5\%, maka ikan akan terjerat oleh jaring. Ayaz et al. (2010) menjelaskan bahwa hanging ratio 0,4\% lebih memberikan hasil tangkapan lebih banyak daripada hanging ratio yang lebih besar dari 0,4\%. Nuhu dan Yaro (2005) menjelaskan bahwa hanging ratio antara 40\% - 50\% memberikan pengaruh yang signifikan terhadap hasil tangkapan. Berdasarkan nilai hanging ratio (E1) dan hanging ratio (E2) dari jaring bombo cakalang, maka jaring ini akan memuntal dan menjerat ikan hasil tangkapan, sehingga ikan sulit terlepas dari jaring bombo cakalang.

Desain dan kontruksi alat tangkap perlu mempertimbangkan nilai gaya apung dan gaya tenggelam dari bahan yang digunakan. Besarnya gaya apung dan gaya tenggelam akan menentukan kedudukan alat tangkap saat dioperasikan. Kedua gaya tersebut disesuikan pula dengan target tangkapan ikan. Apabila target alat tangkap tersebut ikan pelagis maka diperlukan gaya apung yang tinggi. Apabila target alat tangkap tersebut ikan demersal maka dibutuhkan gaya tenggelam yang tinggi. Berat jenis suatu benda akan menentukan besar kecilnya gaya apung dan gaya tenggelam yang ditimbulkan saat berada di perairan termasuk bombo cakalang.

Hasil analisis gaya apung dan gaya tenggelam dari jaring bombo cakalang diperoleh nilai gaya apung (B) sebesar 1,037 Kgf dan gaya tenggelam (S) sebesar 0,303 Kgf. Berdasarkan hasil analisis tersebut dapat dilihat bahwa nilai gaya apung lebih besar dari gaya tenggelam. Hal ini sesuai dengan target tangkapan ikan pada bombo cakalang yaitu jenis-jenis ikan pelagis.

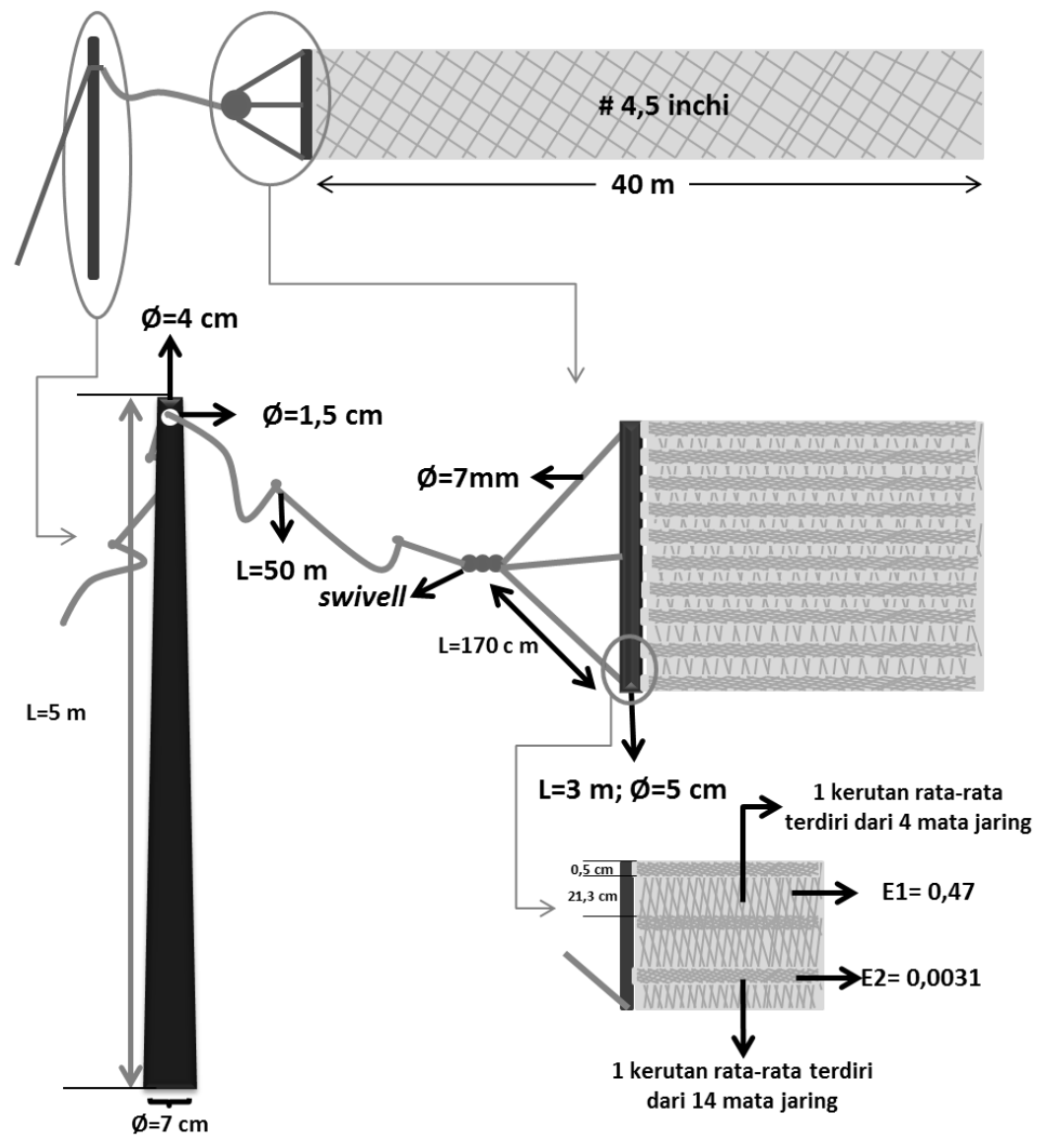

Gambar 3 Konstruksi alat tangkap bombo cakalang 
Tabel 1 Ukuran jaring nylon monofilamen (PA)

\begin{tabular}{clc}
\hline No & \multicolumn{1}{c}{ Item } & Ukuran \\
\hline 1 & Jenis Jaring nylon monofilamen (PA) & \\
2 & Panjang $(\mathrm{m})$ & 40 \\
3 & Lebar $(\mathrm{m})$ & 3 \\
4 & Jumlah mata jaring horisontal & 457 \\
5 & Jumlah mata jaring vertikal & 60 \\
6 & Mesh size (inchi) & 4,5 \\
7 & Diameter benang (mm) & 0,35 \\
8 & Nomor benang & 35 \\
9 & Berat jaring $(\mathrm{Kg})$ & 3 \\
\hline
\end{tabular}

Tabel 2 Spesifikasi ukuran bingkai jaring bombo cakalang

\begin{tabular}{clcc}
\hline No & & Item & Ukuran \\
\hline 1 & Panjang $(\mathrm{m})$ & & 3 \\
2 & Diameter $(\mathrm{cm})$ & 5 \\
4 & Berat $(\mathrm{Kg})$ & 2 \\
\hline
\end{tabular}

Tabel 3 Spesifiksi tali olor bombo cakalang

\begin{tabular}{|c|c|c|}
\hline No & Item & Spesifikasi \\
\hline 1 & Panjang (m) & 50 \\
\hline 2 & Diameter (mm) & 7 \\
\hline 3 & Arah pintalan tali & S \\
\hline
\end{tabular}

Tabel 4 Spesifikasi tiang penyangga bombo cakalang.

\begin{tabular}{clc}
\hline No & \multicolumn{1}{c}{ Item } & Ukuran \\
\hline 1 & Panjang $(\mathrm{m}) \quad$ & 5 \\
2 & Diameter tiang atas $(\mathrm{cm})$ & 4 \\
3 & Diameter tiang bawah $(\mathrm{cm})$ & 7 \\
\hline
\end{tabular}

\section{Daerah Penangkapan Ikan Bombo Cakalang}

Perairan Desa Iwoimendaa merupakan salah satu perairan yang terletak di pesisir Teluk Bone. Daerah penangkapan bombo cakalang berada pada koordinat 0378'77"03'79'44" Lintang Selatan dan $121^{\circ} 068$ '32" - 121'110'07" Bujur Timur. Suhu permukaan laut (SPL) berkisar antara $25^{\circ} \mathrm{C}$ $28^{\circ} \mathrm{C}$. Salinitas berkisar antara $31 \%$ - 33\%o.

Nugraha dan Mardlijah (2008) menjelaskan bahwa daerah penyebaran ikan cakalang berada di daerah tropik dan subtropik, dan di Indonesia ikan cakalang banyak ditemukan di Perairan Sulawesi. Bubun et al. (2014) dan Bubun et al. (2015) menjelaskan bahwa kondisi perairan di Sulawesi Tenggara bagian timur (SPL)) berkisar $24^{\circ} \mathrm{C}-29^{\circ} \mathrm{C}$, salinitas 32\%o-34\%o, dan klorofil-a berkisar 0,1 $\mathrm{mg} / \mathrm{m}^{3}-0,4 \mathrm{mg} / \mathrm{m}^{3}$. Dimana kondisi perairan ini menjadi daerah penangkapan optimum untuk jenis ikan pelagis besar termasuk ikan cakalang. Jufri et al. (2014) dan Angraeni et al. (2014) menjelaskan bahwa daerah penangkapan ikan cakalang optimum di perairan Teluk Bone pada kisaran SPL $29,9^{\circ} \mathrm{C}$
- $31^{\circ} \mathrm{C}$ dengan kandungan klorofil-a pada kisaran $0,12 \mathrm{mg} / \mathrm{m}^{3}-0,22 \mathrm{mg} / \mathrm{m}^{3}$. Agusliana et al. (2016) menjelaskan bahwa tracking daerah penangkapan ikan cakalang di Perairan Barat Laut Banda lokasi yang paling dominan berada pada arah Timur Pulau Wawonii, dimana pergerakan suhu hangat berasal dari arah selatan Laut Banda (Kepulauan Wakatobi) dan suhu dingin berasal dari Laut Banda.

Hasil penelitian para ahli menjelaskan bahwa wilayah perairan Sulawesi Tenggara baik yang berbatasan langsung dengan WPP 713 Teluk Bone maupun WPP 714 Laut Banda merupakan habitat yang cocok untuk spesies ikan cakalang. Berdasarkan hasil penelitian dengan pengukuran SPL dan salinitas dapat dijelaskan bahwa perairan Desa Iwoimendaa merupakan daerah penangkapan ikan yang optimum untuk spesies ikan cakalang.

\section{Metode Penangkapan Bombo Cakalang}

Unit penangkapan ikan bombo cakalang dalam melakukan operasi penangkapan dibantu dengan sarana transportasi perahu 
motor bercadik yang dilengkapi dengan tiang penyangga pada lambung kiri dan kanan perahu. Panjang perahu motor 10 meter dan lebar 1 meter. Kekuatan mesin motor 20 HP $40 \mathrm{HP}$. Lambung kapal lebih ramping dengan tujuan agar perahu motor dapat bergerak cepat di perairan. Penambahan tiang penyangga pada lambung kiri dan kanan perahu dimaksudkan sebagai penyeimbang stabilitas perahu saat operasi penangkapan. Model perahu bombo cakalang dapat dilihat pada Gambar 4.

Metode penangkapan ikan berdasarkan mekanisme tertangkapnya ikan pada alat tangkap merupakan kombinasi antara menjerat (tangling) dan menjebak (trapping) ikan agar tertangkap pada alat tangkap. Tertangkapnya ikan pada alat tangkap berdasarkan pendekatan pada tingkah lakun ikan, bombo cakalang menggunakan prinsip kerja deception (menipu), dimana ikan terjebak pada alat tangkap sebab ikan tidak menyadari adanya alat tangkap.

Pengoperasian alat tangkap bombo cakalang dalam satu perahu motor hanya terdiri dari dua orang yaitu pemilik kapal dan Anak Buah Kapal (ABK). Operasi penangkapan bombo cakalang dilakukan dua trip dalam sehari. Trip pertama mulai pukul 06.00 - 12.00 WITA. Trip kedua pada pukul 14.00 - 17.00 WITA. Trip pertama pukul 05.30 WITA nelayan bombo cakalang melakukan persiapan bahan bakar dan ransum. Pada pukul 06.00 WITA nelayan meninggalkan fishing base menuju daerah penangkapan ikan (fishing ground) yang ditempuh kurang lebih satu jam. Setelah tiba di fishing ground nelayan mulai melakukan setting.

\section{Setting Bombo Cakalang}

Setting bombo cakalang dimulai dengan menarik jaring menggunakan tali olor agar terpasang di bagian atas tiang penyangga. Setelah jaring terpasang, maka jaring diuraikan sampai melayang seperti layanglayang, dimana bagian bawah ujung jaring berada di atas permukaan air. Proses setting bombo cakalang dapat dilihat pada Gambar 5 .

Posisi jaring sudah terpasang sempurna, maka kapal terus berjalan menyusuri perairan dengan kecepatan kapal 10 knot. Setelah melihat tanda-tanda alam dengan banyaknya burung-burung laut di atas permukaan air, maka kecepatan kapal ditambah menjadi 17 knot. Penambahan kecepatan kapal mengikuti swimming speed dari ikan target, agar tidak ketinggalan saat ikan sudah membentuk schooling di fishing ground. Pada saat perahu sudah berada catchable area, selanjutnya tali olor dilepaskan agar jaring dapat menjebak (trapping) dan menjerat ikan target tangkapan. Lama waktu yang dibutuhkan dalam menjerat (tangling) ikan dengan bombo cakalang sekitar 10 menit kemudian hauling. Pelepasan tali olor bersamaan dengan mematikan mesin perahu motor. Tujuan mesin dimatikan pada saat pelepasan tali olor yaitu :

1. Tali olor menjadi kendur saat jaring berada di perairan;

2. Jaring tidak terseret saat berada di perairan sehingga terget tangkapan dapat terjerat dengan sempurna di dalam jaring;

3. Jarak antara perahu dengan jaring tidak terlalu jauh sehingga memudahkan saat hauling.

Penempatan posisi alat tangkap saat akan memasuki schooling ikan dipengaruhi oleh arah renang schooling ikan. Apabila arah kapal searah dengan arah renang schooling ikan, maka kapal langsung melewati schooling ikan tersebut. Akan tetapi bila arah kapal memotong arah renang ikan, maka jaring diletakkan di bagian depan arah renang ikan yang menjadi tujuan penangkapan. Pada saat alat tangkap berada pada posisi yang tepat yaitu jaring berada pada cakupan area penangkapan (catchable area) terhadap schooling ikan, maka jaring diturunkan dengan melepas tali penarik sehingga jaring menutup schooling ikan dan memungkinkan ikan terjerat mata jaring pada bagian operculum (gilled), terjerat pada bagian keliling tubuhnya (wedged) ataau bagian tubuh lainnya.

\section{Hauling Bombo Cakalang}

Hauling merupakan kegiatan penarikan alat tangkap ke atas geladak kapal. Setelah hasil tangkapan ikan berhasil terjerat pada badan jaring bombo cakalang, maka dilakukan hauling bombo cakalang. Proses hauling dimulai dengan menarik tali olor sampai badan jaring naik di atas perahu motor. Saat hauling perlu diperhatikan arah naiknya jaring di atas perahu. Jaring ditarik melalui lambung bagian kanan kapal. Hal ini dilakukan agar jaring tidak terbawa oleh arus dan tersangkut pada baling-baling perahu motor. Proses hauling dapat dilihat pada Gambar 6. 
Hauling alat tangkap berkisar $\pm 10-25$ menit, kegiatan ini dilakukan dengan cara mengerutkan jaring sehingga badan jaring dapat digenggam, kemudian jaring ditarik naik ke atas perahu sambil melepaskan hasil tangkapan atau jaring dinaikkan saja ke atas, pelepasan hasil tangkapan dari alat tangkap setelah jaring berada di atas perahu secara keseluruhan. Akan tetapi, apabila schooling ikan terlihat padat maka jaring ditarik saja naik di atas perahu tanpa melepaskan hasil tangkapan. Selanjutnya nelayan melakukan pemasangan alat tangkap lainnya untuk proses penangkapan berikutnya. Oleh karena itu, nelayan bombo cakalang biasanya membawa alat tangkap satu sampai tiga buah badan jaring bombo cakalang dengan mesh size yang sama yaitu 4,5 inchi dan disimpan di dalam karung plastik.

Tahap setelah penarikan jaring selesai, jaring sudah berada di atas perahu, maka dilakukan pengambilan hasil tangkapan dengan mengeluarkan ikan dari jeratan atau belitan alat tangkap. Pengambilan hasil tangkapan dari jaring bombo cakalang harus tetap memperhatikan kualitas dari ikan akibat terjerat jaring. Selanjutnya ikan yang telah dilepaskan dari jaring dimasukkan kedalam palka yang berisi es. Hal ini diakukan agar mutu hasil tangkapan dapat dipertahankan sehingga ikan masih dalam kondisi segar dan tetap bernilai ekonomis tinggi saat dipasarkan.

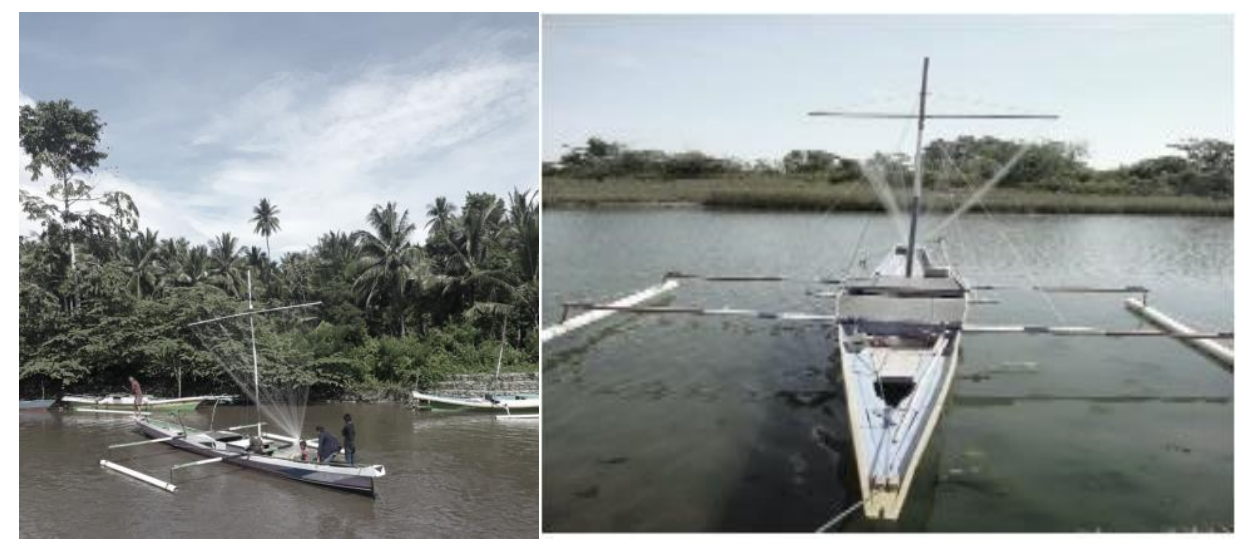

Gambar 4 Model perahu bombo cakalang

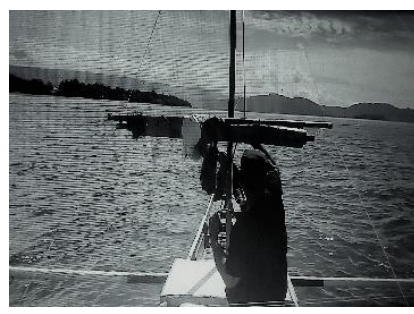

A

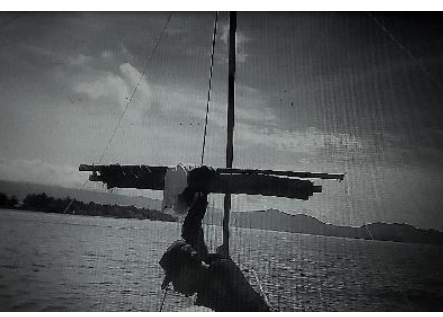

B

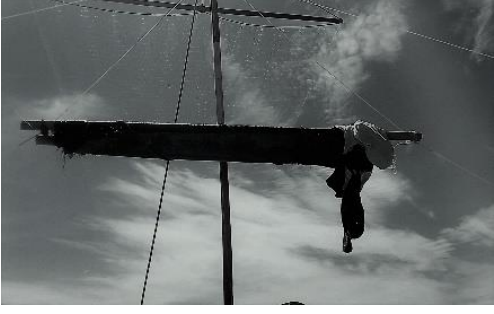

C

Gambar 5 Setting bombo cakalang : (A) penarikan tali olor; (B) Tali olor diikat pada kaki tiang penyangga; $(C)$ jaring bombo cakalang terpasang di ujung atas tiang penyangga
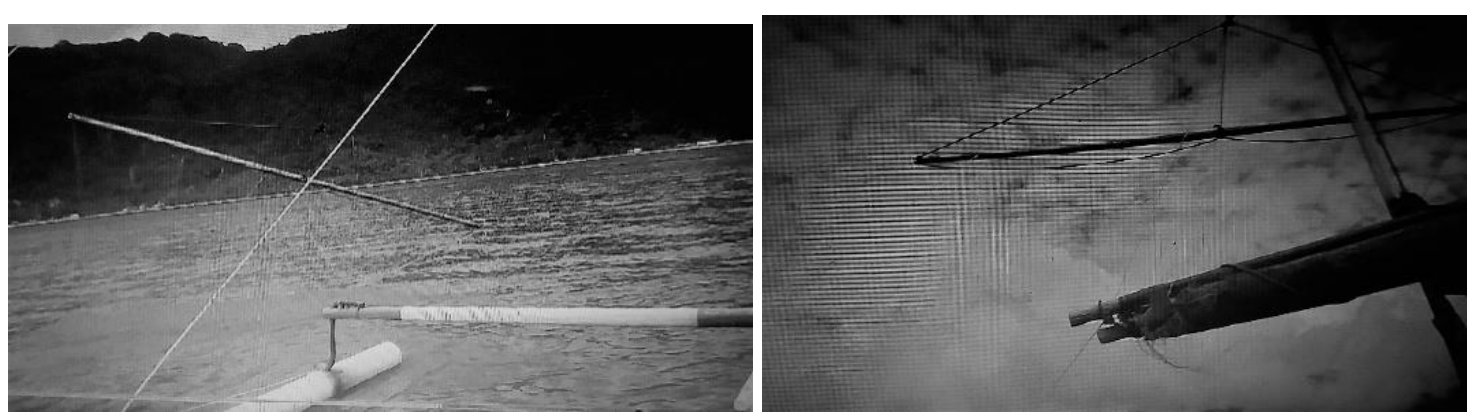

Gambar 6 Hauling bombo cakalang 


\section{PEMBAHASAN}

Usaha penangkapan ikan cakalang merupakan usaha penangkapan yang memiliki nilai komersil dengan menggunakan berbagai alat tangkap baik tradisional maupun modern. Nelayan cakalang di Desa Iwoimendaa melakukan usaha penangkapan ikan dengan bombo cakalang menjadi pilihan prioritas. Hal ini terkait dengan desain konstruksi yang sederhana dan mudah dioperasikan dengan nelayan setempat. Desain konstruksi bombo cakalang yang merupakan perpaduaan alat tangkap gill net dan troll line menjadi salah satu bentuk pengkayaan inovasi nelayan dalam mengembangkan kegiatan usaha perikanan tangkap. Pemanfaatan sumberdaya ikan cakalang pada beberapa penelitian berbeda-beda sesuai dengan kebiasaan nelayan dan kondisi daerah penangkapan ikan. Rochman et al. (2015) menjelaskan bahwa secara komersial ikan cakalang ditangkap dengan menggunakan pukat cincin (purse seine), jaring insang (gill net) dan pancing ulur (handline). Mallawa et al. (2014) menjelaskan bahwa pemanfaatan ikan cakalang di perairan di perairan Flores menggunakan berbagai alat tangkap yaitu alat tangkap yaitu huhate (pole and line), pancing tangan (hand line), pancing tonda (trolling line), payang (tradistional seine net), jaring kolor (purse seine), jaring insang hanyut (drift gill net) dan kadang tertangkap dengan alat tangkap bagan Rambo (giant boat lift net). Rahmat (2007) menjelaskan bahwa nelayan penangkap cakalang di Perairan Bacan menngunakan alat tangkap huhate (pole and line), pancing ulur (hand line), tonda (troll line), dan pukat cincin (purse seine). Susanto et al. (2012) menyebutkan bahwa nelayan di Teluk Bone melakukan penangkapan ikan cakalang menggunakan alat tangkap huhate (pole and line). Bubun dan Mahmud (2015) menyebutkan bahwa ikan cakalang merupakan salah satu hasil tangkapan pukat cincin yang dioperasikan di perairan bagian timur Sulawesi Tenggara.

Kegiatan penangkapan ikan cakalang pada beberapa alat tangkap umumnya menggunakan umpan sebagai alat bantu penangkapan, baik umpan alami maupun umpan buatan. Hal ini dapat dilihat pada pengoperasian alat tangkap pancing seperti pole and line, troll line, hand line. Susanto et al. (2012) menjelaskan bahwa dalam kegiatan penangkapan ikan cakalang dapat menggunakan umpan alami dan umpan buatan. Penggunaan alat tangkap bombo cakalang dalam menangkap cakalang tidak menggunakan alat bantu baik berupa umpan maupun light fishing. Alat tangkap ini hanya mengutamakan keahlian dan keterampilan nelayan dalam menjebak ikan dengan cara mengejutkan ikan agar masuk dalam jaring dan tidak dapat meloloskan diri.

\section{KESIMPULAN}

Hasil penelitian disimpulkan bahwa teknologi penangkapan ikan bombo cakalang yaitu:

1. Bahan alat penangkapan ikan bombo cakalang yaitu jaring dari bahan nylon monofilamen (PA), bingkai jarring dari bamboo, tali kolor dari multifilamen polyethylene (PE) dan tiang penyangga dari kayu "tiro tasi"

2. Konstruksi alat tangkap bombo cakalang terdiri dari jaring dengan hanging ratio $(E 1)$ sebesar 0,47 dan (E2) sebesar 0,0031, bingkai jaring (pelapung), tali kolor, tiang penyangga, gaya apung seesar $1,037 \mathrm{Kgf}$ dan gaya tenggelam sebesar $0.303 \mathrm{Kgf}$.

3. Metode penangkapan ikan adalah menggunakan prinsip menjebak (trapping), menjerat (tangling) dan deception (menipu) ikan target.

4. Daerah penangkapan ikan di pesisir Teluk Bone pada koordinat $03^{\circ} 778^{\prime} 77^{\prime \prime}$ 03'791'44" Lintang Selatan dan $21^{\circ} 068^{\prime} 32^{\prime \prime}$ - 121110'07" Bujur Timur. Suhu permukaan laut (SPL) berkisar antara $25^{\circ} \mathrm{C}-28^{\circ} \mathrm{C}$. Salinitas berkisar antara $31 \%$ - 33\%o.

\section{SARAN}

Penelitian terkait teknologi penangkapan bombo cakalang masih perlu dilakukan beberapa kajian. Kajian yang dimaksud antara lain tingkat keramahan lingkungan, strategi pengembangan dan pengelolaan dan kelayakan usaha penangkapan ikan menggunakan bombo cakalang.

\section{UCAPAN TERIMA KASIH}

1. Lembaga Penelitian dan Pengabdian Masyarakat Universitas Muhammadiyah Kendari sebagai fasilitator dalam kegiatan penelitian. 
2. Kepala Desa Iwoimendaa sebagai fasilitator dalam pelaksanaan penelitian terkait pengumpulan data sekunder nelayan bombo cakalang.

3. Jurnal Marine Fisheries sebagai wadah penerbitan Jurnal Nasional Terakreditasi

\section{DAFTAR PUSTAKA}

Agusliana MSE, Tadjuddah M, Mustafa A. 2016. Sebaran Suhu Permukaan Laut dan Tracking Daerah Penangkapan Ikan Cakalang di Perairan Barat Laut Banda. Jurnal Manajemen Sumber Daya Perairan. 2(1): 41-49

Angraeni, Rezkyanti NI, Safruddin, Zainuddin M. 2014. Analisis Spasial dan Temporal Hasil Tangkapan Ikan Cakalang (Katsuwonus pelamis) dan Thermal Front pada Musim Peralihan di Perairan Teluk Bone. Junal IPTEKS PSP. 1(1): $20-27$

Ayaz A, Altinagac U, Ozekinci U, Cengiz O, Oztekin A. 2010. Effects of Hanging ratio on Gill Net Selectivity for Anular Sea Beam (Diplodus anularis) in The Northern Aegean Turkey. Journal of Animal and Vaterinary Advances. 9(7): 1137 - 1142

Bubun RL, Mahmud A. 2015. Komposisi Hasil Tangkapan Pukat Cincin Hubungannya dengan Teknologi Penangkapan Ikan Ramah Lingkungan. Marine Fisheries. 6(2): 177-186.

Bubun RL, Simbolon D, Nurani TW, Wisudo SH. 2015. Terbentuknya Daerah Penangkapan Ikan dengan Light Fishing. Journal Airaha. 4(1): 27-36

Bubun RL, Simbolon D, Nurani TW, Wisudo SH. 2014. Tropik Level pada Daerah Penangkapan Ikan yang Menggunakan Light Fishing di Perairan Sulawesi Tenggara. Marine Fisheries. 5(1) : 5766 .

Bubun RL. 2014. Terbentuknya Daerah Penangkapan Ikan dalam Perikanan Light fishing dan Dampaknya terhadap Perikanan [tesis]. Pascasarjana. Bogor. Institut Pertanian Bogor.

Jamal M, Sondita MFA, Haluan J, Wiryawan B. 2011. Pemanfaatan Data Biologi
Ikan Cakalang (Katsuwonus pelamis) dalam Rangka Pengelolaan Perikanan Bertanggung Jawab di Perairan Teluk Bone. Jurnal Natur Indonesia. 14(1):107-113

Jufri A, Amran MA, Zainuddin M. 2014. Karakteristik Daerah Penangkapan Ikan Cakalang pada Musim Barat di Perairan Teluk Bone. Junal IPTEKS PSP. 1(1):1 - 10.

Kusumasteti E, Sardiyatmo, Kurohman F. 2017. Analisis Pengaruh Perbedaan Perendaman Mata Jaring Polyamide (PA) Monofilamen No.35 Mesh Size 3,5 Inch pada Air Tawar, Air Laut dan Solar terhadap Kekuatan Putus (Breaking Strength) dan Kemuluran (Elongation). Journal of Fisheries Resources Utilization Management and Technology. 6(4): $20-29$

Mallawa A, Amir F, Zainuddin M. 2014. Keragaan Biologi Populasi Ikan Cakalang (Katsuwonus pelamis) yang Tertangkap dengan Purse Seine pada Musim Timur di Perairan Laut Flores. Jurnal IPTEKS PSP. 1 (2): 129-145.

Martasuganda S. 2008. Jaring Insang (Gillnet). Departemen Pemanfaatan Sumberdaya Perikanan dan Pusat Kajian Sumberdaya Pesisir dan Lautan. Bogor. Institut Pertanian Bogor

Nugraha B, Mardlijah S. 2008. Beberapa Aspek Biologi Cakalang (Katsuwonus Pelamis) yang Didaratkan di Bitung, Sulawesi Utara. Bawal. 2(1): 45-50.

Nuhu, MB, Yaro I. 2005. Selection of efficient hanging ratios of gillnet on fish catch in Lake Kainji, as means of alleviating poverty among artisanal fishermen in Nigeria. In: 19th Annual Conference of the Fisheries Society of Nigeria (FISON), 29 Nov - 03 Dec 2004, Ilorin, Nigeria: 64-72.

Pertiwi MF, Sardiyatmo, Kurohman F. 2017. Analisis Pengaruh Perbedaan Hanging ratio dan Lama Perendaman Jaring Insang (Gill Net) terhadap Hasil Tangkapan Ikan Cendro (Tylosurus melenotes blk ) di Kepulauan Seribu DKI Jakarta. Journal of Fisheries Resources Utilization Management and Technology. 6(4):195-204. 
Rahmat E. 2007. Penggunaan Pancing Ulur (Hand Line) untuk Menangkap Ikan Pelagis Besar di Perairan Bacan, Halmahera Selatan. Buletin Teknik Likayasa. 6(1): 29-33

Rochman F, Nugraha B, Wujdi A. 2015. Pendugaan Parameter Populasi Ikan Cakalang (Katsuwonus Pelamis, Linnaeus, 1758) di Samudera Hindia Selatan Jawa. Bawal. 7(2): 77-85

Sembiring W, Fitri ADP, Wijayanto D. 2016. Analisis Teknis dan Finansial Usaha Perikanan Tangkap Trammel Net dengan Fishing Base di Pelabuhan Perikanan Pantai (PPP) Morodemak. Journal of Fisheries Resources Utilization Management and Technology. 5(6): $32-42$

Susanto EY, Boesono H, Dian A. 2012. Pengaruh Perbedaan Penggunaan Umpan terhadap Hasil Tangkapan Ikan Cakalang (Kastsuwonus pelamis) pada Alat Tangkap Huhate di Perairan Ternate Maluku Utara. Journal of Fisheries Resources Utilization Management and Technology. 1(1): 138-147. 